\title{
WATER-PRESSURE COUPLING OF SLIDING AND BED DEFORMATION: II. VELOCITY-DEPTH PROFILES
}

\author{
By R.B. ALLEY*
}

(Geophysical and Polar Research Center, University of Wisconsin-Madison,

Madison, Wisconsin 53706-1692, U.S.A.)

ABSTRACT. Basal motion of a glacier resting on an unconsolidated bed can arise from sliding between ice and bed, ploughing of clasts through the upper layer of the bed, pervasive deformation of the bed, or shearing across discrete planes in the bed. Theoretical analyses and limited observations of soft-bedded glaciers not dominated by supply of channelized melt water from the surface suggest that sliding will be slow if the bed contains abundant clasts in the $1-10 \mathrm{~mm}$ size range, and that high velocities by ploughing are unlikely though possible. Pervasive deformation usually will account for $60-100 \%$ of the basal velocity, and the strain-rate will be proportional to the basal shear stress and inversely proportional to the square or cube of the effective pressure. These hypotheses are based on results of part $I$ in this series, and allow modeling of Ice Stream B, West Antarctica, in part III of this series.

\section{INTRODUCTION}

Recent glaciological and glacial-geological studies have shown that improved understanding of glacial systems requires better knowledge of how ice interacts with unconsolidated subglacial sediments. The current three-part series explores ice-sediment interactions in the absence of channelized surficial melt water reaching the bed and presents testable hypotheses about this situation; we do not consider the more difficult case of moulins supplying water to the bed.

In part I (Alley, 1989), I hypothesized that in the absence of channelized melt-water supplies, if aquifers beneath a wet-based glacier on an unconsolidated bed were inefficient compared to the supply of basal melt water, then a distributed basal water system with low effective pressure would develop at the ice-sediment interface. In this paper I discuss how such a water system will affect partitioning of basal velocity between sliding, ploughing of clasts, and pervasive and discrete deformation of subglacial sediments. Then in part III (Alley and others, 1989) we use the known and inferred characteristics of Ice Stream $B$ to make specific hypotheses about that ice stream.

\section{SLIDING}

Most wet-based glaciers are restrained mainly by interaction with the roughness of their beds. An inefficient aquifer beneath a wet-based glacier will cause water to accumulate at the ice-bed interface until the accumulations become interconnected and allow drainage along that interface. Such an interconnected water system will have little effect on sliding velocity if it occupies only a small fraction, $f$, of the bed area and thus does not reduce the bed roughness significantly. Sliding resistance is a

* Present address: Earth System Science Center and Department of Geosciences, The Pennsylvania State University, University Park, Pennsylvania 16802, U.S.A. complicated function of size, shape, and arrangement of bed-roughness elements (Nye, 1969; Weertman, 1969; Kamb, 1970; Fowler, 1987; Lliboutry, 1987a, b; and earlier papers by most of these authors), but in general $f$ must be large to allow fast sliding. For a given bed roughness, an increase in $f$ requires an increase in water pressure so that water pressure exceeds ice normal stress over a larger fraction of the bed, as argued in part $I$.

The interconnected fractional area, $f$, must increase with the average water-film thickness, $d$, in a manner that depends on bed geometry. For a glacial till, a reasonable assumption is that the bed contains spherical clasts in different size classes, with all clasts in any class having the same size. The clasts with radii $R_{j}$ occupy volume fraction of the till $V_{j}$ for each of the $j$ size classes, pores occupy volume fraction $V_{p}$, and

$$
V_{\mathbf{p}}+\sum_{j} V_{j}=1 .
$$

In an isotropic medium, areal fraction occupied on a section plane equals volume fraction for any size class (Underwood, 1970), and I will assume that this applies at the ice-till interface. I also will assume that each clast forms a hemispherical bump of radius $R_{j}$. With these assumptions, the dependence of $f$ on $d$ can be approximated for any specified grain-size distribution as

$$
f(d)=V_{\mathrm{p}}+\sum_{j=1}^{i} V_{j}
$$

where $i$ is chosen so that $d \geqslant R_{i}$, the clast radius in the $i$ th size class, but $d \leqslant R_{i}+1$. The base of the glacier is chosen as the base of the ice, so the porosity is assumed ice-free and the water system always occupies $V_{p}$.

It commonly is observed that tills contain a wide range of grain-sizes, from clay to boulders, and that the volume fractions are similar in size classes with logarithmically scaled radii (but of ten with bimodal peaks; Sugden and John, 1976, p. 228-31). One simple relation that meets these criteria is to divide clasts into seven size classes with radii $R_{j}=10^{-6}, 10^{-5}, \ldots, 10^{0} \mathrm{~m}$, with one-tenth of the till volume in each of the seven size classes and with $30 \%$ of the volume in pores. This allows Equation (2) to be approximated continuously as

$$
f=1+0.1 \log _{10} d
$$

where $d$ is in meters. Equation (2) does not allow for progressive submergence of individual clasts as $d$ increases, whereas Equation (3) is a crude attempt to do so. Equation (3) is useful for calculating examples, and we will argue in part III that it is a reasonable assumption to use for Ice Stream B. Of course, the equivalent of Equation (2) or (3) should be written as accurately as possible for any subglacial sediment under consideration.

Typical water-film thicknesses beneath a fast-moving glacier are likely to be 1-10 mm (e.g. Weertman, 1972; 
Weertman and Birchfield, 1982; part III), which from Equation (3) gives $f \approx 0.7$. From Weertman sliding theory (e.g. Weertman, 1964, 1969), the sliding velocity $u_{s}$, under such conditions is approximately

$$
u_{\mathrm{s}}=K_{\mathrm{s}} \tau_{\mathrm{b}}^{2} d
$$

where $\tau_{\mathrm{b}}$ is the basal shear stress; the pre-factor $K_{\mathrm{s}}$ can be evaluated from the bed roughness and depends on the controlling obstacle size, which typically is $1-10 \mathrm{~mm}$ (Weertman, 1964, 1969). Using Weertman's preferred constants, including an ice-hardness parameter of $0.17 \mathrm{bar}^{-3} \mathrm{a}^{-1}$, and assuming that interference of stress fields around clasts reduces the effective bed roughness by a factor of 4 below that expected from the assumed roughness without interference (Brown and others, 1987), the roughness assumed in Equation (3) with a basal shear stress of tenths of a bar $\left(10^{4}-10^{5} \mathrm{~Pa}\right)$ and with $f=0.7(d=1-10 \mathrm{~mm})$, gives a sliding velocity of $u_{\mathrm{S}}=0(1-10 \mathrm{~m} / \mathrm{a})$.

This calculated sliding velocity is low compared to similar calculations for typical bedrock beds considered by Weertman (e.g. Weertman, 1969) and other workers. The reason is that the spacing between obstacles of near the controlling size is small on a till bed as compared to a polished granite, for example.

Limited examples seem to support this contention that till beds cause glacier sliding to be slow. At Breiđamerkurjökull, Boulton and Hindmarsh (1987) showed that motion between markers in the base of the ice and the top of the underlying, deforming till accounts for only about $10 \%$ of the basal velocity of about $30 \mathrm{~m} / \mathrm{a}$; because of the finite size of the markers used, the sliding velocity is $\leqslant 3 \mathrm{~m} / \mathrm{a}$. Similarly, beneath Blue Glacier, Engelhardt and others (1978) observed little or no slip between basal ice and the top of a "mobile sub-sole drift", except during periods when the basal water was artificially overpressurized through drilling and the ice was floated off the bed. Notice, however, that natural water-layer thicknesses at the ice-bed interface were not measured at Breiđamerkurjökul or at Blue Glacier.

It also is worth noting that clay-rich tills with few clasts $\geqslant 1 \mathrm{~mm}$ do occur naturally. If small clasts in such tills fail to aggregate into larger units, then $K_{\mathrm{s}}$ and sliding velocities for such tills could be quite large. It is the common occurrence of clasts $0(1-10 \mathrm{~mm})$ in radius that makes a till rough to ice.

\section{PLOUGHING}

In addition to sliding (see above) and pervasive bed deformation (see part I and below), a complete treatment of basal processes must consider the possiblity of ploughing. This is a transitional state between sliding and pervasive deformation in which individual clasts in contact with sliding ice are dragged through a till that is deforming locally but not pervasively. Ploughing was described by Boulton and others (1974), and was placed within a theoretical framework by Brown and others (1987). In the discussion that follows, I briefly summarize the discussion of ploughing by Brown and others (1987) and relate it to my treatment of sliding and bed deformation. I find that in most cases rapid ploughing is likely to lead directly to pervasive deformation so that ploughing need not be modeled separately; however, further data on till properties are needed to strengthen this conclusion.

First, I will simplify the ploughing model of Brown and others (1987) and recast it in terms of the variables used in part 1 . Ploughing is initiated when the shear stress on a clast exceeds the local sediment strength on the yield surface for motion of that clast. As before, consider that the bed is composed of clasts in discrete size classes, with all clasts in a class having the same size. Let the average shear stress be $\tau_{b}$, with clasts occupying fractional area $s$ of the bed and water occupying fractional area $f=1-s$. In some arbitrary area $A$, clasts in the $j$ th size class occupy area $s_{j} A$ and support shear force $\tau_{j} A$, so that the local shear stress on a clast in the $j$ th size class is $\tau_{j} A /\left(s_{j} A\right)=$ $\tau_{j} / s_{j}$. Also, let the local effective pressure on the failure surface for motion of a clast be $N_{1 j}$ and the local sediment strength be $N_{1} / a_{1}$, where $a_{1}$ is a geometric factor.
Brown and others (1987) showed that ploughing occurs when the ploughing index $I_{j}^{*} \geqslant 1$, where

$$
I_{j}^{*}=\frac{a_{1}}{N_{1 j}} \frac{\tau_{j}}{s_{j}}
$$

(Brown and others (1987) called the ploughing index $P^{*}$; I use $I^{*}$ to avoid confusion here with pressure and stress terms P.) Brown and others (1987) also showed that

$$
a_{1}=\frac{2 \tan (45-\phi / 2)}{\tan \phi}
$$

where $\phi$ is the angle of internal friction in degrees and cohesion has been assumed to be zero (Brown and others, 1987).

The local effective stress can be approximated by $N_{1 j}=P_{\mathrm{b} j}-P_{\mathrm{w}}$, where $\mathrm{P}_{\mathrm{b} j}$ is the normal stress on the clast and $P_{\mathrm{w}}$ is the water pressure. Subtracting $P_{\mathrm{w}}$ from both sides of equation (A3) in part $I$ and remembering that $N=P_{i}-P_{\mathrm{w}}$ yields

$$
\begin{aligned}
P_{\mathrm{b} j}-P_{\mathrm{w}} & =P_{\mathrm{i}}-P_{\mathrm{w}}+\frac{B \tau_{j}}{s_{j}} \\
N_{1 j} & =N+B \frac{\tau_{j}}{s_{j}}
\end{aligned}
$$

or, substituting for $B$ from equation (22) in part

$$
N_{1 j}=N\left[1+\frac{f}{\tau_{\mathrm{b}}} \frac{\tau_{j}}{s_{j}}\right] .
$$

(Strictly, $P_{\mathrm{b} j}$ measures the vertical stress on a clast but $N_{1 j}$ measures the stress normal to the failure surface of a clast and adjacent materials. This could be corrected for by multiplying $\beta$ by a numerical constant in Equation (7). Brown and others $(1987$, p. 8991) estimated $K$, the equivalent of $\beta$ in Equation (7), as between 0.1 and 0.44 For hydrostatically pressured water in subglacial sediments of Ice Stream B near the Upstream B camp, we estimate $\beta \approx 0.4$ (part III). The extra constant in Equation (7) thus should be near unity, and we omit it.)

It is convenient to define a new parameter, $\zeta_{j}$, as

$$
\zeta_{j} \equiv \frac{\tau_{j}}{\tau_{\mathrm{b}}} .
$$

$\left(\zeta_{j}\right.$ is the fraction of the average shear force (i.e. the force on a typical area $A$ ) that is supported by clasts in the $j$ th size class.) Then combining Equations (5), (8), and (9) gives

$$
I_{j}^{*}=\frac{\tau_{\mathrm{b}}}{N}\left[\frac{a_{1} \zeta_{j}}{s_{j}+\zeta_{j} f}\right] .
$$

The onset of ploughing occurs at $I_{j}^{*}=1$, i.e. for

$$
\tau_{\mathrm{b}} \geqslant N \frac{s_{j}+\zeta_{j} f}{a_{1} \zeta_{j}} .
$$

It is of interest to substitute typical numerical values into relationship (11). Weertman (1964) estimated that $\zeta_{j}=$ $1 / 3-1 / 2$ for controlling obstacles, which will be the first to plough (Brown and others, 1987). For the till bed introduced in Equation (3), $s_{j}=0.1$, and $f=0.3$ for water occupying pore spaces only. Taking $\zeta_{j}=1 / 2$ and $\phi=25^{\circ}$ as typical for till (Brown and others, 1987 ) yields $a_{1}=2.7$ and $\tau \geqslant 0.2 \mathrm{~N}$ to allow ploughing.

An increase in shear stress above this minimum value will cause clasts of other sizes to plough and thus will increase the fraction of the bed ploughing. In the 
mathematical limit of the entire bed ploughing, the average behavior can be calculated by letting $s_{j}=s$ and $\zeta_{j}=1$ in relationship (11), and remembering that $s+f=1$. Then, from relationship (11), $\tau_{\mathrm{b}} \geqslant N / a_{1}$.

Ploughing of the entire bed is crudely equivalent to development of a continuous shear plane at the base of the ploughing clasts (but see below). It differs from pervasive deformation only in that continuous motion is restricted to the uppermost layer of clasts; deeper material disturbed by passage of large clasts returns to a static condition between disturbances. For $\phi=25^{\circ}$ and $a_{1}=2.7$ in a cohesionless till, the theory of Brown and others (1987) predicts that ploughing of the entire bed would occur for $\tau_{b} \geqslant 0.4 N$. In comparison, the criterion for pervasive deformation is

$$
\tau_{\mathbf{b}} \geqslant N \tan \phi
$$

or for $\phi=25^{\circ}, \tau_{b} \geqslant 0.5 N$.

Caution must be used in extending the ploughing theory of Brown and others (1987) to high ploughing fraction. For example, the theory does not allow for overlap of failure surfaces of adjacent ploughing clasts, which would occur if most clasts were ploughing. Ignoring such complications, however, the calculations above suggest the not-so-startling result that a shear plane can be initiated in a till at a shear stress less than that required for pervasive deformation. Shear planes are observed in some tills (e.g. MacClintock and Dreimanis, 1964; Boulton and Hindmarsh, 1987), lending credibility to this result. (It is unknown whether the processes of $100 \%$ ploughing causing a shallow shear plane in till actually occur.) However, this result suggests that there is a narrow range of basal shear stress $\left(0.4 N \leqslant \tau_{b}<0.5 N\right)$ in which ploughing of the entire bed can occur without pervasive deformation. This range is of similar width $(0.1 N$ to $0.2 N)$ for $\tan \phi=0.2$, and narrows to zero at $\tan \phi=0.75$.

Another important complication must be introduced here. Laboratory experiments and field observations show that deformation of a till (or any granular material) causes it to dilate, and that a water-saturated till is weaker in its dilated state than in its collapsed, lodged state (Boulton and others, 1974; Boulton and Hindmarsh, 1987). When deformation ceases, a dilated till tends to collapse back to its stronger, lodged state (Boulton and Dent, 1974). Brown and others (1987) used $\phi=25^{\circ}$ as a typical value for till that is not actively deforming and suggested $\phi \approx 11^{\circ}$ ( $\tan \phi$ $=0.2$ is a plausible minimum for till; Alley and others (1987a) suggested that $\phi \approx 11^{\circ}$ is the most likely value for the dilated, deforming till postulated beneath Ice Stream $B$. If $\tan \phi \approx 0.2$ applies to a deforming till, then $\tau_{\mathrm{b}}>0.2 \mathrm{~N}$ is sufficient to maintain deformation of an already deforming, non-cohesive till

Boulton and others (1974) noted that a ploughing clast will dilate till locally by disturbing other clasts both adjacent and subjacent to it. If the time required for any locally dilated region to collapse back to its lodged state is long compared to the time until that region is disturbed by another ploughing clast, then that region will remain dilated and soft. The time between passages of ploughing clasts will decrease as the ploughing fraction increases with increasing shear stress. The possibility thus exists that ploughing will cause a transition to pervasive deformation at $\tau_{b}<0.5 N$, the strength of lodged, undisturbed till. (It also is possible that ploughing will reduce the shear stress required to initiate further ploughing.)

$I$ thus find that $T \geqslant c_{1} N$ will initiate ploughing, where $c_{1} \approx 0.2$, that an increased ploughing fraction requires $c_{1}>0.2$, but that pervasive till deformation will be sustained for $c_{1} \approx 0.2$. It is likely that $c_{1}$ passes through a maximum at some intermediate level of ploughing on the way to pervasive deformation, although any maximum must be less than or equal to 0.5 , the value for pervasive deformation of a lodged till. To calculate the behavior between the onset of ploughing and pervasive deformation would require comparison of the disturbance rate from ploughing to the rate of collapse of dilated till following disturbance, but the collapse rate is unknown.

However, it is of some interest to calculate the disturbance rate. Consider the till bed introduced above, and suppose that ploughing is occurring only for clasts of radius $10 \mathrm{~mm}$, which probably approximates the critical size on Ice
Stream B. Such clasts occupy about $10 \%$ of the surface area of the ice-bed interface, and have a mean spacing in any direction (assuming isotropy) of about $120 \mathrm{~mm}$ (Underwood, 1970 , p. 83). At a basal velocity of about $500 \mathrm{~m} \mathrm{a}^{-1}$ (typical of Ice Stream $B$ ), the average delay time between passage of clasts ploughing at a velocity close to the ice-stream velocity would be about $2 \mathrm{~h}$ at any spot. This delay time would be reduced slightly if $I$ allowed for the increase in ploughing area caused by ploughing clasts pushing material ahead of them. Also, an increase in the fraction of the bed ploughing would reduce the delay, until there would be little delay if the entire bed were moving. Thus, if the time for a dilated till to collapse to a lodged state is long compared to $2 \mathrm{~h}$ for the ice velocity and till bed assumed here, ploughing would dilate the bed and lead to pervasive deformation with little or no increase in shear stress; however, if the collapse time is short compared to $2 \mathrm{~h}$, the shear stress would need to increase substantially above the minimum for ploughing to mobilize a large fraction of the bed before pervasive deformation could begin. Unfortunately, I know of no available data to estimate the collapse time.

It is also of interest to ask under what conditions ploughing can lead to large basal velocities without pervasive deformation occurring. Brown and others (1987) have presented indirect evidence for ploughing velocities of about $500 \mathrm{~m} \mathrm{a}^{-1}$ without pervasive deformation beneath the former Vashon glacial lobe, whereas the direct evidence of Boulton and Hindmarsh (1987) shows pervasive deformation without significant ploughing beneath Breiđamerkurjökull.

As noted above, Brown and others (1987) have proposed that ploughing clasts support a large fraction of the basal shear stress, occupy $0(10 \%)$ of the bed, and cover a size range centered on the controlling obstacle size $\left(0\left(10^{-3}-10^{-2} \mathrm{~m}\right)\right)$. Brown and others (1987) implicitly used a zero-viscosity (or a perfect-plasticity) model in which the ploughing velocity of a clast approaches the ice velocity if the shear stress on the clast equals the minimum value needed to cause motion. Real materials typically exhibit non-zero viscosity and finite exponent in power-law creep, such that strain-rate increases with stress; a Bingham model (velocity increasingly linearly with shear stress above the yield strength) or some other similar model is usually assumed (e.g. Boulton and Hindmarsh, 1987). In either case, a large ploughing velocity without pervasive deformation would require a viscosity some orders of magnitude less than that measured at Breiđamerkurjökull (Boulton and Hindmarsh, 1987) or inferred for Ice Stream B (Alley and others, 1987b). To see this, consider the case of the UpB camp on Ice Stream $B$, where we have inferred that $N \approx 50 \mathrm{kPa}$, and $\tan \phi \approx 0.2$ (Alley and others, 1987a; Blankenship and others, 1987). The Bingham equation is

$$
\tau_{\mathrm{e}}-\tau^{*}=\mu_{\mathrm{b}} \frac{u_{0}}{z_{1}}
$$

where $\tau_{\mathrm{e}}$ is the effective shear stress causing deformation, $\tau^{*}$ is the shear strength, $u_{0}$ is the velocity at the top of a deforming layer $z_{1}$ thick, and $\mu_{\mathrm{b}}$ is the Bingham viscosity of the layer. For pervasive deformation

$$
\begin{aligned}
\tau_{\mathrm{e}} & =\tau_{\mathrm{b}} \\
\tau^{*} & =N \tan \phi
\end{aligned}
$$

where cohesion again has been taken to be zero. For ploughing of the $j$ th size class, from Equations (5)-(9)

$$
\begin{aligned}
\tau_{\mathrm{e} j} & =\frac{\zeta_{j} \tau_{\mathrm{b}}}{s_{j}} \\
\tau_{j}^{*} & =\frac{N}{a_{1}}\left[1+\frac{f \zeta_{j}}{s_{j}}\right] .
\end{aligned}
$$

At $\mathrm{UpB}, \quad u_{\mathrm{b}} \approx 500 \mathrm{~m} \mathrm{a}^{-1}, \quad z_{1} \approx 6 \mathrm{~m}$ for pervasive deformation, and $z_{1} \approx 0.02 \mathrm{~m}$ for ploughing of controlling obstacles. The Bingham viscosity for pervasive deformation at $\mathrm{UpB}$ then is about $120 \mathrm{~Pa}$ a. Taking $s_{j}=0.1, f=0.3, \zeta_{j}$ 
$=0.5$ for ploughing of controlling obstacles only through a bed with water only in pore spaces, then $\mu_{b}=2.0 \mathrm{~Pa}$ a for ploughing through till with $\phi=25^{3}$ (lodged till) and $\mu_{\mathrm{b}}=$ $3.2 \mathrm{~Pa}$ a for $\phi=11^{\circ}$ (dilated till); these values would be reduced to $\mu_{\mathrm{b}}=0.67 \mathrm{~Pa} \mathrm{a}$ and $\mu_{\mathrm{b}}=2.9 \mathrm{~Pa} \mathrm{a}$ if $f=0.7$. Even letting $N=0, \mu_{\mathrm{b}}=4 \mathrm{~Pa}$ a is required to obtain $u_{0}=$ $500 \mathrm{~m} \mathrm{a}^{-1}$ by ploughing. If ploughing of controlling clasts is to yield a velocity similar to that inferred for pervasive deformation at $\mathrm{UpB}$, then the till viscosity must be reduced by one to two orders of magnitude. (For comparison, typical Bingham viscosities for Breiđamerkurjökull calculated from Equation (13) and data from Boulton and Hindmarsh (1987) are around $3000 \mathrm{~Pa}$, or an order of magnitude higher than inferred at $\mathrm{UpB}$, but Fahnestock and Humphrey (1988) reported a linear viscosity of about $30 \mathrm{~Pa}$ a beneath Columbia Glacier.) If more of the bed is allowed to plough, $s_{j}$ will increase more rapidly than $\zeta_{j}$ on the ploughing fraction because the first size class to plough supports the largest fraction of the shear stress. This will decrease $\left(\tau_{\mathrm{e} i}-\tau_{j}^{*}\right)$ and thus require a lower Bingham viscosity to achieve the same ploughing velocity as calculated from Equation (13).

This calculation places constraints on possible ploughing behavior, provided that ploughing obeys a Bingham-type deformation law. (Similar results to those above are also obtained using a linear-viscous model or the model preferred by Boulton and Hindmarsh (1987).) For a given shear stress and water pressure at the ice-bed interface, the velocity from pervasive deformation of a till $\geqslant 0(1 \mathrm{~m})$ thick is likely to be at least $1-2$ orders of magnitude faster than that from ploughing through the same till. High ploughing velocities without pervasive deformation are likely only if the shear stress is less than the yield strength for pervasive deformation but the Bingham viscosity is at least 1-2 orders of magnitude lower than that measured at Breidamerkurjökull or inferred at UpB.

The continuum treatment of granular materials used here introduces some ambiguity at large ploughing fractions. If clasts in many size classes are ploughing, the matrix through which they plough has a grain-size distribution and properties different from those of the bulk till. However, these differences are minimized when only one size class is ploughing. Note also that ploughing as modeled by Brown and others (1987) occurs through till that is not deforming pervasively and thus is strong, but that $I$ have used viscosities from soft, dilated, pervasively deforming till for comparison. Allowing for this difference would strengthen the conclusion reached above that high velocities through ploughing are unlikely.

To summarize, ploughing of clasts through lodged till will begin for $\tau \geqslant c_{1} N$ with $c_{1} \approx 0.2$, and all clasts in contact with the ice will plough for $c_{1} \approx 0.4$. Initiation of pervasive deformation of an undisturbed till requires $c_{1} \approx 0.5$, but pervasive deformation may be maintained for $c_{1} \approx 0.2$. An interesting, though unproven, hypothesis is that ploughing will dilate and soften till locally, allowing initiation of further ploughing and of pervasive deformation for values of $c_{1}$ somewhat smaller than specified here. High basal velocities through ploughing without pervasive deformation require lower Bingham viscosities in the ploughing layer than have been reported or estimated for modern tills. Based on these considerations, on our previous calculations that most velocity at the Upstream $B$ camp in Ice Stream B arises from pervasive bed deformation (Alley and others, 1987a), and on the observations of basal motion dominated by pervasive deformation at Breiđamerkurjökull (Boulton and Hindmarsh, 1987), we will proceed in part III to model Ice Stream $B$ assuming that ploughing does not contribute significantly to the basal ice velocity.

I do not have enough data to propose hypotheses for the differences between the inferred behavior of the Vashon glacier lobe (ploughing without pervasive deformation; Brown and others, 1987) and of Ice Stream B (pervasive deformation; Alley and others, 1987a). Assuming that both inferences are correct, the difference might lie in till properties, the (lack of) availability of channelized, clean water from surface melt, or the (lack of) ice-marginal effects during glacier retreat. This is an area that clearly merits further study; the probability that abundant surficial melt water reached the bed of the Vashon glacier lobe at discrete points may provide a profitable starting place for such study.

\section{PERVASIVE DEFORMATION}

\section{General considerations}

A sufficiently large basal shear stress will cause pervasive deformation in a subglacial sediment. Such deformation has been observed beneath Breiđamerkurjökull (Boulton and Hindmarsh, 1987) and Columbia Glacier (Meier, 1989), and inferred elsewhere. The velocity-depth profile and thickness of a pervasively deforming till layer are important in determining ice and till fluxes, and may be used in some cases to constrain the flow law for till; however, these topics have received little study to date.

Here I calculate velocity-depth profiles for the likely range of till properties and for both lithostatic and hydrostatic water-pressure gradients. The solutions obtained also apply if water-pressure gradients less than hydrostatic are specified; however, I do not consider the estimation of such gradients, which has been modeled by Boulton and Hindmarsh (1987) and Clarke (1987), among others. I exclude from consideration extrusion flow of till, which might occur if till viscosities were reduced to values typical of surficial debris flows by water pressures essentially equal to overburden pressures. Such flows could not be steady unless restricted to channels narrow compared to the ice thickness, owing to the mechanical instability of extrusion flow (Nye, 1952). Extrusion flow has been modeled by Mellors and Whillans (1986) and Mellors (unpublished), and its geomorphic implications have been discussed by Boulton and Hindmarsh (1987). There is no direct evidence for the existence of such flow, however, and measured and inferred till viscosities at Breiđamerkurjokkull, Blue Glacier, UpB (Alley and others, 1987b), and Columbia Glacier (Fahnestock and Humphrey, 1988) are too high to allow significant extrusion flow (Alley and others, 1987b; Mellors, unpublished).

For this discussion, I adopt the coordinate axes shown in Figure 1, with the origin at the ice-till interface, $z$ positive downward, and $x$ positive in the direction of ice flow. The system is assumed to be two-dimensional; Boulton (1979) discussed three-dimensional effects.

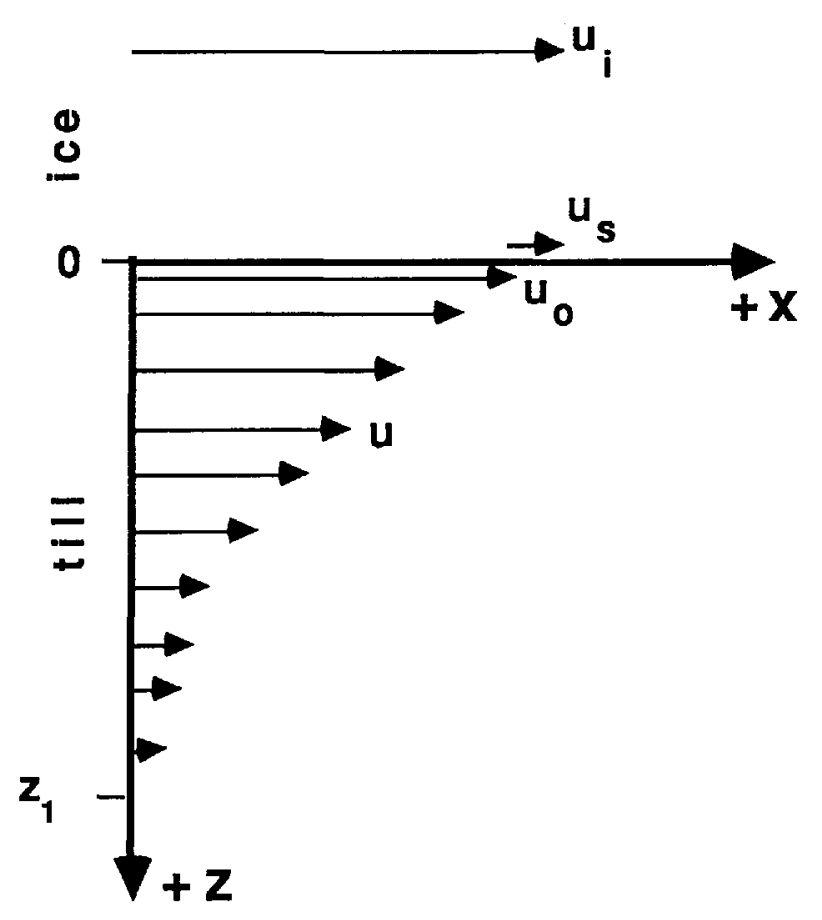

Fig. I. Coordinate axes for till-deformation calculations, with the origin at the ice-till interface (or the top of the till if there is a significant water layer), $z$ positive downward, and $x$ positive in the direction of flow. The ice velocity is $u_{i}$, the sliding velocity is $u_{s}$, the till velocity is $u$, the till velocity at $z=0$ is $u_{0}$, and $u_{i}=u_{s}+u_{0}$ if there is no ice deformation. The pervasively deforming till thickness is $z_{1}$. 
If a fluid occupies communicating pore spaces in a material and is not flowing vertically, then the effective pressure is

$$
N(z)=N_{0}+\Delta \rho g z
$$

where $N_{0}$ is the effective pressure at $z=0$ and $\Delta \rho$ is the difference between the bulk density, $\rho_{b}$, and the pore-fluid density.

In a till that is not deforming, the pore-fluid density is the density of water, $\rho_{w}$, and the effective pressure assumes hydrostatic values given by

$$
N_{\mathrm{H}}(z)=N_{0}+\left(\rho_{\mathrm{b}}-\rho_{\mathrm{w}}\right) g z
$$

Effective pressure increases more rapidly with depth than this if downward porous flow occurs to a deeper, efficient aquifer.

Studies of debris flows suggest that, if the debris framework is deformed rapidly enough, water and fine clasts form an effective fluid in which larger clasts float (Rodine and Johnson, 1976; Hampton, 1979). The fluid density then approaches the bulk density, and $\Delta \rho$ is reduced toward zero. In the limit of very fast deformation, $\Delta \rho=0$ and the fluid can be said to exhibit a lithostatic pressure gradient, giving

$$
N_{\mathrm{L}}(z)=N_{0}
$$

It is unknown whether Equation (17), (18), or some intermediate case applies at the strain-rates that occur beneath glaciers lacking efficient deeper aquifers.

\section{Deforming thickness}

The thickness of a pervasively deforming layer can be limited by three factors: its yield strength, its strain-rate, or a change to a stronger material. The stronger material is the most obvious case; if a thin till directly overlies fresh granite, one would not expect the deforming layer to be thicker than the till.

Deformation of till causes it to dilate and soften (Boulton and others, 1974), but if the strain is not sufficiently rapid the dilated structure will collapse and the till will stiffen (Boulton and Dent, 1974). Alley and others $(1986,1987 a)$ proposed that this must place a limit on the possible deforming thickness; ice continuity limits potential ice velocity, and the minimum strain-rate for dilatancy then should limit the deforming thickness. This idea is speculative, but I will return to it below.

Yield-strength control is better established, and must figure in any full treatment of till properties. If effective pressure increases with depth, then yield strength also increases with depth, typically much more rapidly than does shear stress. If so, then the yield stress must increase above the shear stress at some depth in the till, stopping deformation.

The basal shear stress increases with depth in till according to

$$
\tau_{\mathrm{b}}(z)=\rho_{\mathrm{i}} g(h+z) \alpha_{\mathrm{i}}+\left(\rho_{\mathrm{b}}-\rho_{\mathrm{i}}\right) g z \alpha_{\mathrm{b}}
$$

where $\alpha_{i}$ and $\alpha_{b}$ are the down-stream slopes of the ice-air and ice-till interfaces, respectively, and $\rho_{i}$ and $h$ are the density and thickness of ice, respectively. For a horizontal bed $\left(\alpha_{b}=0\right)$ and a surface slope $\alpha_{i}=0.002$, typical of Ice Stream $B, \tau_{b}$ increases downward at about $20 \mathrm{~Pa} / \mathrm{m}$. By comparison, for hydrostatic water of density $\rho_{W}=$ $1000 \mathrm{~kg} / \mathrm{m}^{3}$ in till of bulk density $\rho_{\mathrm{b}}=2000 \mathrm{~kg} / \mathrm{m}^{3}$ and internal friction $\tan \phi=0.2$, the yield strength increases downward at about $2000 \mathrm{~Pa} / \mathrm{m}$, or about two orders of magnitude faster. It is thus a good approximation to assume that $\tau_{b}$ is constant in till; this can be called the thin-till approximation.

Making this approximation, then the basal shear stress equals the yield stress at depth $z_{2}$ given by

$$
\begin{aligned}
\tau_{\mathrm{b}} & =\left(N_{0}+\Delta \rho g z_{2}\right) \tan \phi+C \\
z_{2} & =\frac{\tau_{\mathrm{b}}-C}{\Delta \rho g \tan \phi}-\frac{N_{0}}{\Delta \rho g} .
\end{aligned}
$$

\section{Velocity-depth profiles}

Most proposed flow laws for shear deformation of water-saturated sediments have the form

$$
\begin{aligned}
& \frac{\partial u}{\partial z}=-K_{\mathrm{b}} \frac{\left(\tau_{\mathrm{b}}-\tau^{*}\right)^{a}}{N^{b}} ; \tau_{\mathrm{b}}>\tau^{*} \\
& \frac{\partial u}{\partial z}=0 ; \quad \tau_{\mathrm{b}} \leqslant \tau^{*}
\end{aligned}
$$

where $u$ is the velocity in the $x$ direction, $K_{\mathrm{b}}$ is a constant (strictly speaking, $K_{\mathrm{b}}$ here is twice the value of $K_{\mathrm{b}}$ in equation (1), part I), and $\tau^{*}$, the yield strength, is given by

$$
\tau^{*}=N \tan \phi+C .
$$

In the thin-till, lithostatic-water case where $\tau_{\mathrm{b}}$ and $N$ are independent of $z$, the velocity varies linearly with depth. If $\tau_{\mathrm{b}}$ is constant but $N$ varies with depth, Equation (21) generates an interesting family of curves.

To investigate this family of curves further, it is convenient to make some definitions. Above, I defined $z_{2}$ as the depth at which the yield strength would equal the shear stress if the till were homogeneous and at least as thick as $z_{2}$. Now $I$ define $z_{1}$ as the thickness of the deforming layer; that is,

$$
\begin{aligned}
& z_{1} \equiv \text { depth to bedrock, } z_{1} \leqslant z_{2} \\
& z_{1} \equiv z_{2} \text {, depth to bedrock }>z_{2}
\end{aligned}
$$

where "bedrock" is any material under a till with a significantly higher yield strength. Combining Equations $(20)-(23)$ gives the general flow law for till as

$$
\begin{aligned}
& \frac{\partial u}{\partial z}=-K_{\mathrm{b}} \frac{\left(\tau_{\mathrm{b}}-\tau^{*}\right)^{a}}{N^{b}} ; z \leqslant z_{1} \\
& \frac{\partial u}{\partial z}=0 ; z>z_{1} .
\end{aligned}
$$

In addition, I define $z_{0}$ to be the depth at which the effective pressure is twice the value at the ice-till interface,

$$
z_{0}=\frac{N_{0}}{\Delta \rho g}
$$

or an appropriate modification if downward water flow occurs. The variable $z_{0}$ measures how rapidly effective pressure increases with depth, $z_{1}$ is the deforming thickness, and $z_{2}$ is the depth at which deformation would cease because of yield strength of the deforming layer.

Returning to Equation (24) with $z<z_{1}$, Equations (20) and (25) allow the deformation to be described by

$$
\frac{\partial u}{\partial z}=-K_{\mathrm{b}}(\tan \phi)^{a} N_{0}^{a}-b \frac{\left[\left[1+\frac{z_{2}}{z_{0}}\right]-\left[1+\frac{z}{z_{0}}\right]\right]^{a}}{\left[1+\frac{z}{z_{0}}\right]^{b}}
$$


$u(z)-u_{0}=-K_{\mathrm{b}}(\tan \phi)^{a} N_{0}^{a}-b \int_{0}^{z} \frac{\left[\left[1+\frac{z_{2}}{z_{0}}\right]-\left[1+\frac{z}{z_{0}}\right]\right]^{a}}{\left[1+\frac{z}{z_{0}}\right]^{b}} \mathrm{dz}$

where $u(0) \equiv u_{0}$. At $z=z_{1}, u$ drops to zero. Letting $z=z_{1}$ in Equation (27), solving for the constant terms $K_{\mathrm{b}}(\tan \phi)^{a} N_{\mathrm{0}}^{a-b}$, and substituting back into Equation (27) yields

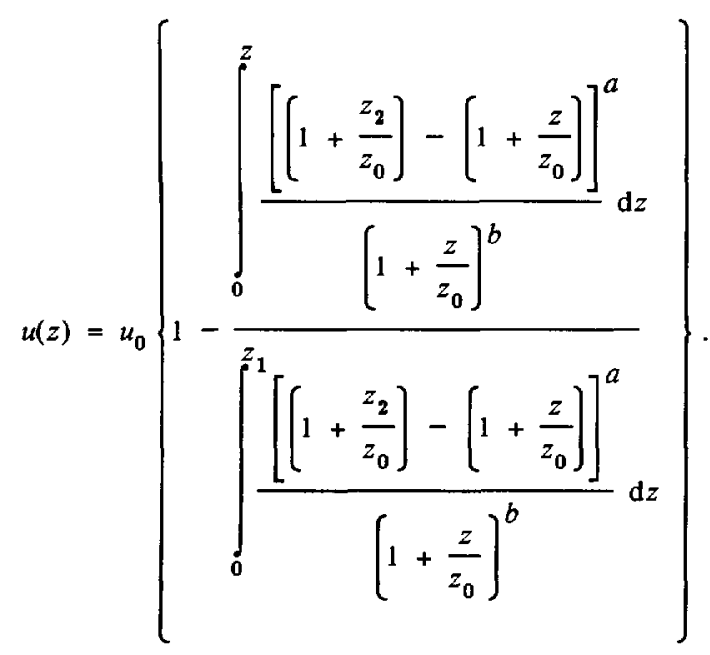

A second integration gives the depth-averaged velocity, $\bar{u}$, as

$$
\bar{u}=\frac{1}{z_{1}} \int_{0}^{z_{1}} u \mathrm{~d} z .
$$

Equation (28) shows that the relative velocity $u / u_{0}$ occurs in a six-dimensional space defined by the powers $a$ and $b$, and the depths $z, z_{0}, z_{1}$, and $z_{2}$. I will restrict further attention to the case $a=1$, appropriate to the Bingham and linear-viscous cases. Boulton and Hindmarsh (1987) measured $N, u_{0}$, and $z_{1}$, and estimated $\tau_{\mathrm{b}}$ for several sites beneath Breiđamerkurjökull, and fitted the data using Equation (24) with $\partial u / \partial z=u_{0} / z_{1}$ and with $\tau^{*}=0$ or $\tau^{*}$ determined from their measurements. Their results were $a=1.33, b=1.80$ for $\tau^{*}=0$, and $a=0.625, b=1.25$ for $\tau^{*}>0$. They did not report errors on these determinations; based on my analysis of their data, I estimate standard errors of $\pm 0.2-0.3$ on $a$ and $b$. If so, then $a=1$ is consistent with their data. Also, $a=1$ allows a good fit to the longitudinal profile of Ice Stream B (see part III). I wish to emphasize that I choose $a=1$ as the mathematically simplest expression that is consistent with the available data, but $I$ do not argue that $a=1$ necessarily is exactly correct.

Taking $a=1$, the integrations in Equations (28) and (29) then can be done for arbitrary values of the parameters $b, z_{0}, z_{1}$, and $z_{2}$, and the variable $z$. Results are listed in Tables $I$ and II in terms of dimensionless variables defined there. The general case is valid for $b \neq 1,2,3$; logarithmic terms arise in $u$ for $b=1,2$ and in $\bar{u}$ for $b=1,2,3$, as shown. In the limit of $z_{1}=z_{2} \quad(\omega=1)$, deformation occurs to bedrock. In the limit of $z_{2} \rightarrow \infty$ $(\omega \rightarrow 0), u$ and $\bar{u}$ are well behaved and give the behavior for a till with no yield strength.

The behavior for selected values of $b$ and the dimensionless variables of Table $I$ is plotted in Figures 2 and 3. Rapid velocity decrease with increasing depth near the top of the till is favored by large values of $b$ and of $x=z_{0} / z_{1}$, which lead to relatively low values of $\bar{u}$ and thus of till flux. The variable $\omega=z_{1} / z_{2}$ determines how

TABLE I. EQUATIONS FOR VELOCITY-DEPTH PROFILES IN TILL WITH $a=1$

$$
\begin{aligned}
& \mathrm{x} \equiv \frac{z_{0}}{z_{1}}, \quad \psi \equiv \frac{z}{z_{1}}, \quad \omega \equiv \frac{z_{1}}{z_{2}} \\
& \mathrm{~b} \neq 1,2:
\end{aligned}
$$

$$
\begin{aligned}
& u(z)=u_{0}\left(1-\frac{\left[\frac{1+\frac{1}{x \omega}}{b-1}\right]\left[1-\left[1+\frac{\phi}{\chi}\right]^{1-b}\right]-\left[\frac{1}{b-2}\right]\left[1-\left[1+\frac{\psi}{\chi}\right]^{2-b}\right]}{\left[\frac{1+\frac{1}{\chi \omega}}{b-1}\right]\left[1-\left(1+\frac{1}{\chi}\right]^{1-b}\right]-\left[\frac{1}{b-2}\right]\left[1-\left[1+\frac{1}{\chi}\right]^{2-b}\right]}\right] \\
& b=1: u(z)=u_{0}\left(1-\frac{\left[1+\frac{1}{x \omega}\right] \ln \left[1+\frac{\psi}{\chi}\right]-\frac{\Phi}{x}}{\left[1+\frac{1}{x \omega}\right] \ln \left[1+\frac{1}{x}\right]-\frac{1}{x}}\right] \\
& b=2: u(z)=u_{0}\left[\begin{array}{c}
\frac{\psi-\frac{1}{\omega}}{x+\psi}+\frac{1}{x \omega}-\ln \left[1+\frac{\psi}{\chi}\right] \\
\frac{1-\frac{1}{\omega}}{x+1}+\frac{1}{x \omega}-\ln \left[1+\frac{1}{x}\right]
\end{array}\right]
\end{aligned}
$$


TABLE II. EQUATIONS FOR AVERAGE VELOCITY IN TILL WITH $a=1$

$$
\begin{aligned}
& x \equiv \frac{z_{0}}{z_{1}} ; \quad \psi \equiv \frac{z}{z_{1}} ; \quad \omega \equiv \frac{z_{1}}{z_{2}} \\
& \mathrm{~b} \neq 1,2,3:
\end{aligned}
$$

$$
\begin{gathered}
\bar{u}=u_{0}\left[1-\frac{\frac{x+\frac{1}{\omega}}{(b-1)}\left[\left(1+\frac{1}{x}\right]^{2-b}-1+\frac{1}{x}(b-2)\right]-\frac{x}{(b-3)}\left[\left[1+\frac{1}{x}\right]^{3-b}-1+\frac{1}{x}(b-3)\right]}{\left[\frac{b-2}{b-1}\right)\left[1+\frac{1}{x \omega}\right]\left[1-\left[1+\frac{1}{x}\right]^{1-b}\right]-\left[1-\left[1+\frac{1}{x}\right]^{2-b}\right]}\right] \\
b=1: \quad \bar{u}=u_{0}\left[1-\frac{\left[x+\frac{1}{\omega}\right]\left[\left(1+\frac{1}{x}\right] \ln \left[1+\frac{1}{x}\right]-\frac{1}{x}\right]-\frac{1}{2 x}}{\left(1+\frac{1}{x \omega}\right) \ln \left[1+\frac{1}{x}\right]-\frac{1}{x}}\right]
\end{gathered}
$$

$$
b=2: \quad \bar{u}=u_{0}\left[1-\frac{2+\frac{1}{x \omega}-x\left[2+\frac{1}{x}+\frac{1}{x \omega}\right] \ln \left[1+\frac{1}{x}\right]}{\frac{1-\frac{1}{\omega}}{x+1}+\frac{1}{x \omega}-\ln \left[1+\frac{1}{x}\right]}\right]
$$

$$
b=3: \quad \bar{u}=u_{0}\left[1-\frac{\frac{x+\frac{1}{\omega}}{\left[1+\frac{1}{x}\right]}-x-1-\frac{1}{\omega}+\frac{1}{x \omega}+2 x \ln \left[1+\frac{1}{x}\right]}{\frac{1}{x \omega}+\frac{2}{1+\frac{1}{x}}-1-\frac{\left(1+\frac{1}{x \omega}\right]}{\left[1+\frac{1}{x}\right]^{2}}}\right]
$$

rapidly the velocity decreases to zero near the base of the deforming layer; large $\omega$ requires that the deeper velocities be almost asymptotic to zero, requiring rapid velocity decrease with depth near the top of the deforming layer and thus small $\bar{u}$. However, the velocity-depth profile is less sensitive to $w$ than to $b$ or $\chi$.

In principle, if till deformation obeys Equation (24) with $a=1$, then one can measure $z_{0}, z_{1}, z_{2}$ (possibly), and $u(z)$, and determine $b$ and $z_{2}$ (if necessary) from comparison between the data and Figure 2. Although no-one has measured all of the necessary parameters in a deforming till and the applicability of Equation (24) is open to question, analysis of the seminal data set of G.S. Boulton and co-workers from Breiđamerkurjökull (e.g. Boulton and others, 1974; Boulton, 1979; Boulton and Hindmarsh, 1987) suggests that this method is workable but difficult.

In Figure 4, I show the velocity-depth data of Boulton and Hindmarsh (1987, fig. 2) re-plotted according to the variables used here. In each case, I have estimated the velocity at the top of the till, $u_{0}$, by interpolating linearly between the velocities of the lowermost marker in the ice and the uppermost marker in the till in Boulton and Hindmarsh (1987, fig. 2). I have also assumed that the thickness of the deforming layer $\left(z_{1}=z_{2}\right)$ is the till thickness above the lowermost marker placed by Boulton and Hindmarsh (1987), although slow motion across discrete shear planes is reported to occur below the lowermost markers.

Comparison of Figures 2 and 4 shows immediately that the real world is more complicated than assumed in
Equation (24). Some of the "wiggles" in the velocity-depth profiles in Figure 4 are caused by proximity to large rigid clasts (e.g. arrays 3 and 4 near $z / z_{1}=0.6$, where the shear strain-rate decreases almost to zero; Boulton and Hindmarsh, 1987). Also, transverse flow may have minor effects on velocity-depth profiles (Boulton, 1979). However, the rapid downward decrease in velocity (large shear strain-rate) near the base of each curve requires a different explanation.

The inflection points (that is, the points where the shear strain-rates pass through minima, which I term inflection points for convenience (Fig. 4)) in the velocitydepth profiles occur at (array 4) or just above (arrays 1, 2, 3) the depths where Boulton and Hindmarsh (1987) observed a downward change in mode of deformation from pervasive creep to shear on discrete planes. The till porosity is relatively high and decreases slowly with increasing depth above the inflection point, but decreases rapidly with depth from near the inflection point to the bottom of the profile (Boulton and Hindmarsh, 1987, fig. 4a).

I suggest that these observations demonstrate the existence of a minimum strain-rate required to maintain dilation (Alley and others, 1986, 1987a). Remember that till can be transformed from a compact, strong state to a dilated, weak state by strain in the presence of excess water (so that the material remains saturated) and this is reversible if the pore water can escape during compaction (Boulton and Dent, 1974). It is reasonable to expect that if the strain-rate in a dilated material becomes too low, then the collapse process will be dominant over dilation, causing the till to lose porosity and gain strength. The feed-back related 

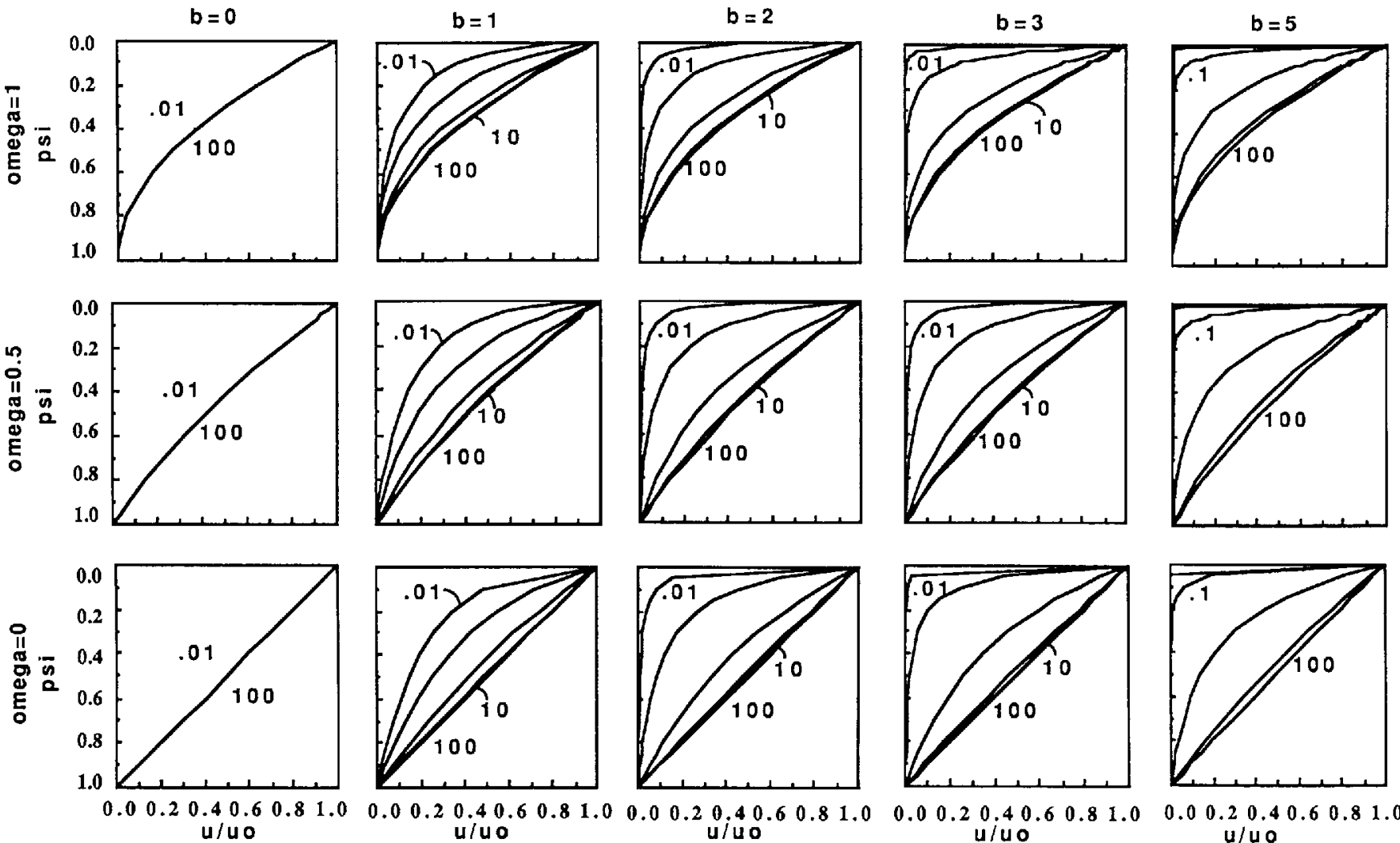

Fig. 2. Velocity-depth plots. Plots of $u / u_{0}$ (horizontal till velocity normalized by velocity at top of till) are shown against relative depth, $\psi\left(=p s i=z / z_{1}\right.$, where $z_{1}$ is the base of pervasive deformation and $z$ is the depth). The exponent $a=1$ in Equation (24), and each column of plots is headed by the value of the exponent $b$ used in that column; each row uses the value of $\omega$ shown at the left $(\omega)$ omega $=z_{1} / z_{2}$, where $z_{2}$ is the depth at which the shear stress would equal the strength of the pervasively deforming till). Each plot contains curves for $x=0.01,1,10,100$, where $\chi=z_{0} / z_{1}$ and $z_{0}$ is the depth at which the effective pressure, $N$, in the till is twice the value at the ice-till interface, $N_{0}$. Curves for $b=0$ are independent of $\chi$, as shown. For $b \geqslant 1$, curves are identified $b y$ $\chi$ values placed to their lower right, unless otherwise indicated. The limiting case of $\chi=0, b>0$ gives a curve plotting on the top and left coordinate axes (as does $b \rightarrow \infty$ ); the $\chi=0.01$ curves for $b=5$ are close to this behavior. In the limit of $x \rightarrow \infty$, curves with $b \neq 0$ become identical to the $b=0$ curves; the $\chi=10$ and $\chi=100$ curves for small $b$ are essentially at this limit and plot quite close together. All curves are monotonic and smooth; slight irregularities in the figure arise from the computerized plotting package used.

to this (slow strain $\rightarrow$ collapse $\rightarrow$ stronger till $\rightarrow$ slower strain) should cause the transition zone between soft dilated, pervasively deforming till and strong, collapsed till without pervasive deformation to be relatively thin. However, discrete shearing is possible under conditions that suppress pervasive deformation (see discussion on ploughing, above), and thus might occur in and just below this transition zone. Calculations by J.S. Walder (personal communication, 1988) suggest that such slow shearing at the base of a pervasively deforming till is possible over consolidated rock as well.

The minimum strain-rate hypothesis then predicts that pervasive deformation will cease when the strain-rate falls to some critical value (or the effective pressure and shear strength rise to some critical value compared to the shear stress), that the strain-rate just above this depth will exceed the expected strain-rate just above the depth where $\tau=\tau^{*}$ $\left(z=z_{2}\right)$ in Equation (24), that the porosity will decrease rapidly near this depth, and that discrete shearing may occur near and below this depth. The agreement between hypotheses and observations suggests strongly that a minimum strain-rate for dilation does exist and is reached near the inflection points shown in Figure 4.

This discussion suggests that $\tan \phi$ (and possibly $C$ and $N)$ are inverse functions of $\partial u / \partial z$, and that the true flow law is likely to be a very complicated entity, as discussed by Clarke (1987). It remains possible, however, that Equation (24) (and its solutions in Table I) can be modified to provide a reasonable approximation of the actual behavior. Boulton and Hindmarsh (1987) showed that the porosity decreases downward only slowly in the upper $\approx 70 \%$ of the deforming layer before dropping rapidly into the zone of discrete shearing, and porosity should be a good proxy for till strength for a given till. Suppose we let $z \equiv$ $z_{3}$ be the depth to the bottom of the relatively homogeneous upper part of the layer, so that the strain-rate falls to the minimum value to maintain dilation $(|\partial u / \partial z|=$ $\left.|\partial u / \partial z|_{\text {min }}\right)$ at $z=z_{3}$. Assume further that $\tan \phi, C$, and $z_{0}$ are independent of $z$ in this upper, pervasively deforming region. Then Equation (23) can be rewritten as

$$
\begin{aligned}
& z_{1} \equiv \text { depth to bedrock, } z_{1}<z_{3} \\
& z_{1} \equiv z_{3}, \text { depth to bedrock }>z_{3}
\end{aligned}
$$

and Equation (24) still describes pervasive deformation.

Here $z_{1}$ is the thickness of the pervasively deforming layer, $z_{2}$ is the depth at which the yield strength of this pervasively deforming layer would equal the basal shear stress, and $z_{3}$ is the depth at which the pervasive deformation ceases (or would cease) because of strain-rate control. This means that $z_{1} \leqslant z_{3}<z_{2}$.

With these assumptions, Figure 2 and Table I still describe the deformation, but the variable $\omega=z_{1} / z_{2}$ cannot be larger than $z_{3} / z_{2}$ and thus is less than 1. Also, the velocity $u$ must be understood as arising from pervasive deformation; discrete shear at the base of the pervasively deforming layer provides an additional velocity just as discrete shear at the top of the layer provides the additional sliding velocity.

The data of Boulton and Hindmarsh (1987) show that the sediment porosity (and by inference, the softness of the sediment) does decrease slowly downward in the pervasively deforming layer. Thus, calculations following Equation (24) 

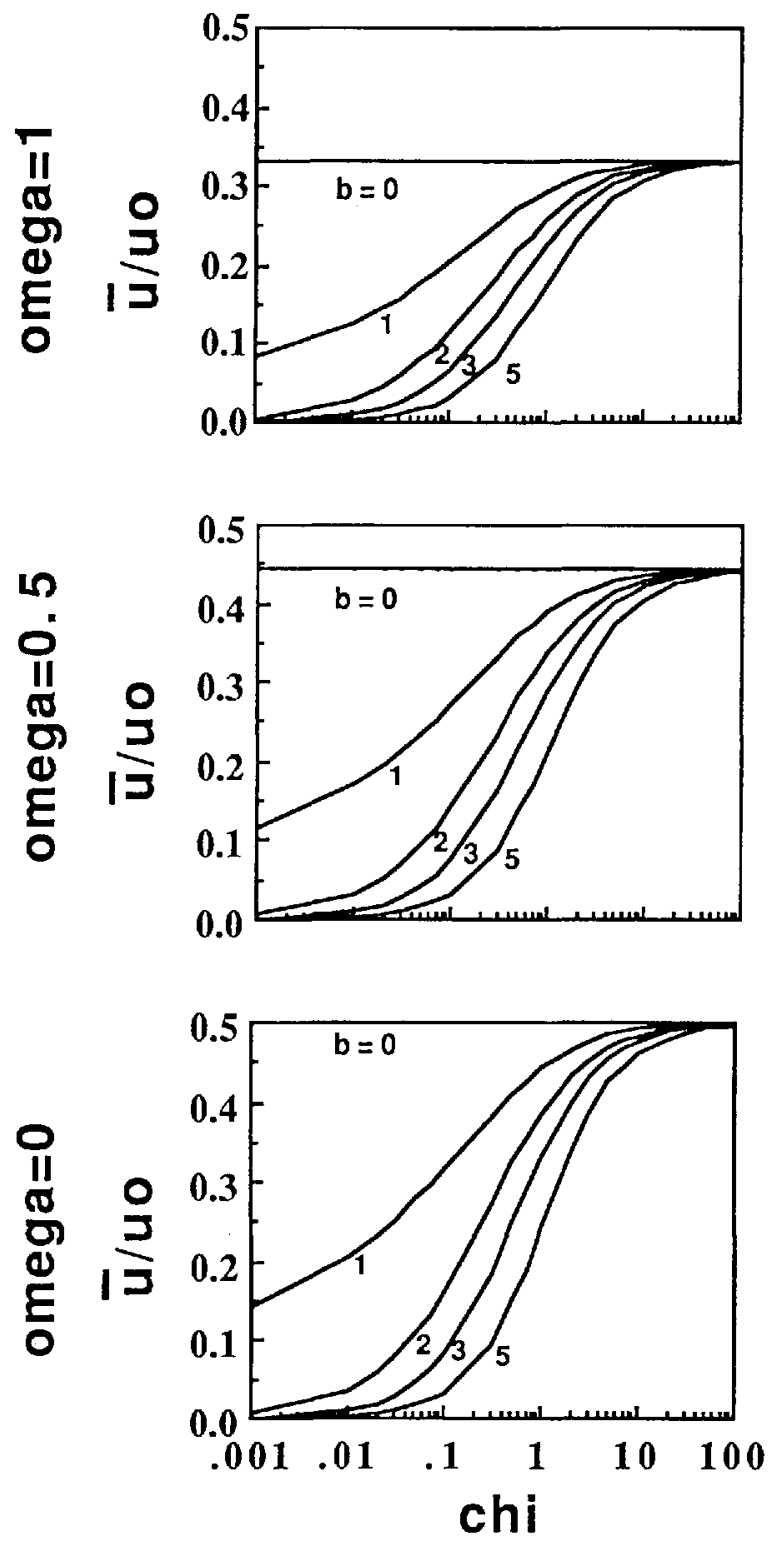

Fig. 3. Depth-averaged velocity of pervasive deformation, $\bar{u}$. normalized by $u_{0}$, plotted against $\chi(=$ chi $)$, for different values of $\omega$ (=omega): all variables are defined in the caption to Figure 2. Each plot contains curves for $b=0,1,2,3$, and 5 (indicated to the lower right of the appropriate curve) assuming $a=1$. The average velocity (and thus till flux) decreases with increasing $b$ and $\omega$ and with decreasing $x$. The likely values of $x, b$, and $w$ discussed in this paper and in part III give $\bar{u} / u_{0} \approx 0.1-0.5$.

and using the appropriate values of constants will underestimate the curvature of measured velocity-depth profiles. Stated differently, if $z_{0}, z_{1}, z_{2}$, and $z_{3}$ are known and $b$ is chosen to provide the best match between calculated and observed velocity-depth profiles, then this value of $b$ will place an upper limit on the true value.

Bearing this in mind, we now can attempt to fit the velocity-depth profiles for the pervasively deforming layer at Breiđamerkurjökull, and thus to constrain the flow law for till. The inflection points in Figure 4, which I argue are good approximations of $z_{3}$, occur at $\phi=z / z_{1} \approx 0.8$ (array 1), 0.6 (array 2), 0.75 (array 3), and 0.7 (array 4). Defining these points to be $z_{3}$ and the deformational velocity, $u$, at these points to be zero yields the curves shown in Figure 5. From the data and calculations of Boulton and Hindmarsh (1987), the effective pressure at the ice-till interface is $N \approx 40 \mathrm{kPa}$, and the effective pressure would double at $z_{0} \approx 3 \mathrm{~m}$. The pervasively deforming layer is $z_{1} \approx 0.4 \mathrm{~m}$ thick, so $\chi=z_{0} / z_{1} \approx 7$.

The reader can compare Figures 2 and 5 to estimate which values of $\omega$ and $b$ in Figure 2 predict curves similar to those in Figure 5. I do not try a detailed, statistical

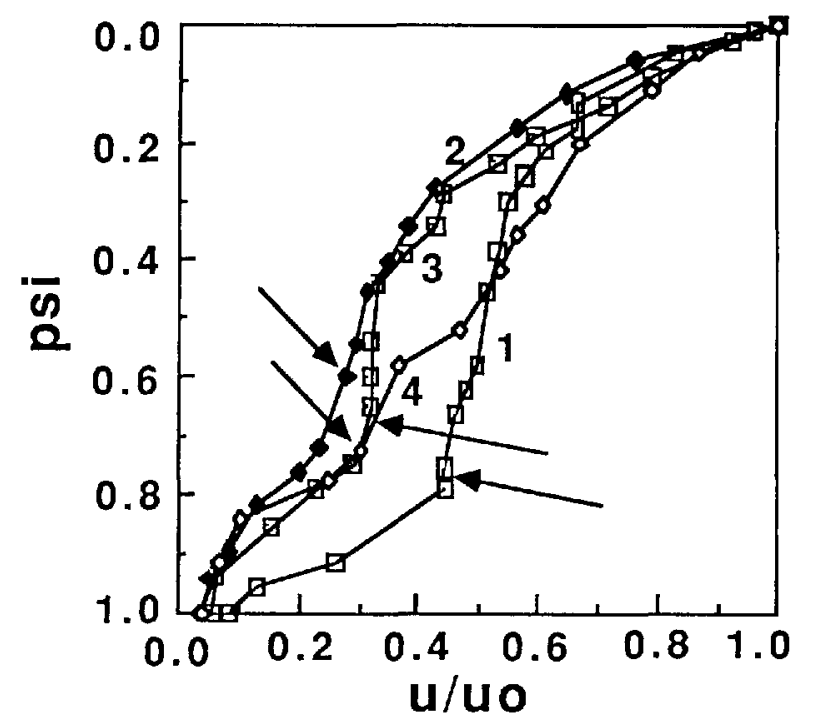

Fig. 4. Measured velocity-depth profiles of till beneath Breiđamerkurjökull (Boulton and Hindmarsh, 1987, fig. 2) plotted on the scale defined in the caption to Figure 2. Numbers 1-4 refer to the arrays $1-4$ shown in figure 2 of Boulton and Hindmarsh (1987). The inflection points that $I$ identify with the base of pervasive deformation are indicated by arrows.

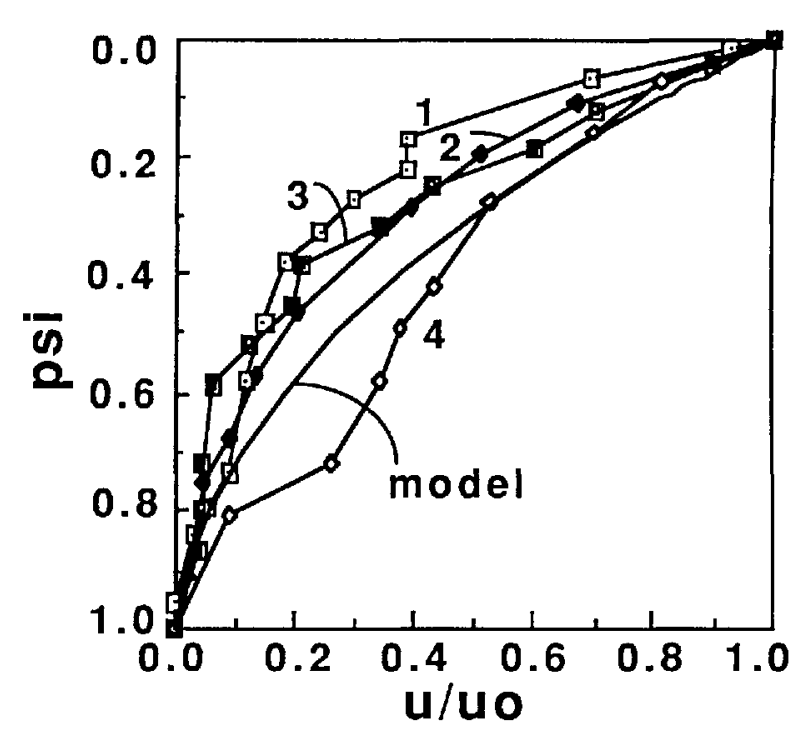

Fig. 5. Curves from Figure 4 above the inflection points, recalculated so that $u=0, \psi=1$ at the inflection points. The curve labeled "model" is calculated from Equation (28) with $a=1, b=2, x=7$, and $\omega=0.9$.

curve-fitting exercise because of the large variability in the observed profiles and the uncertainties introduced by depth variation of till properties, the presence of large, rigid clasts, and the likely occurrence of transverse flow. However, by inspection, I find that $b \approx 2-3, \omega \approx 0.9$ provides a good fit. Reducing $\omega$ requires an increase in $b$ to maintain reasonable agreement between model and observed curves, but the quality of the fit deterioriates slowly from $(\omega, b)=(0.9,2)$ to $(0.5,5)$, and becomes very bad for smaller $\omega$. It is notable that the values $I$ find that give a good fit $(0.9,2-3)$ give $b$ close to what we would expect based on the between-site fit of Boulton and Hindmarsh (1987), especially if we reduce $b$ slightly from $2-3$ to allow for the effect of slow variation of till properties with depth in the pervasively deforming layer. I therefore suggest that a curve-fitting exercise such as this is not a sensitive test for flow-law constants, but does aid in constraining these constants.

If we accept $(\omega, b)=(0.9,2)$ as a working hypothesis, two further calculations suggest themselves. First, at $z=z_{1}$, the slope of the model curve gives $|\partial u / \partial z| \approx 5 \mathrm{a}^{-1}$ as an estimate for $|\partial u / \partial z|_{\min }$, the minimum strain-rate required 
to maintain pervasive till dilation and deformation.

Secondly, the estimate $\omega \approx 0.9$ can be used to constrain the yield strength of the dilated till. Because $\omega=z_{1} / z_{2}$ and $z_{1} \approx 0.4 \mathrm{~m}, z_{2} \approx 0.45 \mathrm{~m}$. At this point, $\tau_{\mathrm{b}}=N \tan \phi+C$ for the dilated till. Boulton and Hindmarsh (1987) (also see Boulton and Dent, 1974; Boulton and others, 1974; Boulton, 1979) measured $C \approx 4 \mathrm{kPa}, \tan \phi \approx 0.625$, and presented data that allow us to estimate $N(0.45 \mathrm{~m}) \approx 46 \mathrm{kPa}$; however, the method used to measure $\tan \phi$ probably over-estimates that number (Alley and others, 1987a). If $\tau_{b}$ were known accurately, then we could use $N\left(z_{2}\right), C$, and $T_{\mathrm{b}}$ to estimate $\tan \phi$. Unfortunately, the measurements of Boulton and Hindmarsh (1987) were made within a few ice thicknesses of the glacier terminus, where effects of longitudinal deviatoric stresses (Nye, 1967) or back-pressure from small push moraines can cause the basal shear stress to deviate significantly from the usual assumption $\tau_{b}=\rho_{i} g h \alpha$, where $\rho_{i}, h$, and $\alpha$ are the ice density, thickness, and surface slope, respectively. (Boulton and Hindmarsh (1987) did not report the method they used to estimate $\tau_{b}$; possible uncertainties from near-terminus effects probably broaden the likely errors in their determination of flow-law exponents beyond the limits I cited above.) Nevertheless, if we assume as an exercise that the usual basal shear-stress formula applies, then $\tau_{b} \approx 30 \mathrm{kPa}$ and $\tan \phi=0.56$. A similar calculation with $\omega=0.5, z_{2}=0.8$ would give $\tan \phi=0.51$. These calculations certainly involve large errors, but in principle calculations such as these can be used to constrain till strength better.

\section{HYPOTHESES}

My discussion of velocity-depth profiles in deforming tills has covered a number of aspects. More than anything else, I believe it demonstrates the need for well-designed, direct studies of subglacial deformation. The studies of Boulton and co-workers (e.g. Boulton and Dent, 1974; Boulton and others, 1974; Boulton, 1979; Boulton and Hindmarsh, 1987) clearly are the standard against which all other efforts will be judged, but it is equally clear that this single project does not constrain the full range of possible behaviors.

Despite our large uncertainties regarding till properties, the discussion above does provide some information on till deformation. It also allows me to propose the following hypotheses, most of which should be testable in future field programs:

Till beds containing abundant clasts in the $1-10 \mathrm{~mm}$ size range will be "rough" to a glacier and will cause sliding velocities to be low.

For a typical till, clast ploughing is initiated at $\tau_{b}>$ $0.2 N$, but usually leads to initiation of pervasive deformation at $0.2 N<\tau_{\mathrm{b}} \leqslant 0.5 \mathrm{~N}$; pervasive deformation is sustained for $\tau_{b}>0.2 N$.

Pervasive deformation requires that the strain-rate exceed some minimum value, which may be on the order of $5 \mathrm{a}^{-1}$

Deformation by shearing across discrete surfaces occurs beneath pervasively deforming sediments in a thick unconsolidated column, and may account for a significant fraction (perhaps $* 30 \%$ ) of the total deformational velocity; the possibility of discrete shearing between a pervasively deforming till and rigid bedrock should be considered.

Comparison of measured and calculated velocity-depth profiles can be used to constrain the flow law for pervasive deformation, although an exact fit is unlikely; a model with $\left(\tau-T^{*}\right) / N^{2}$ seems to fit the velocity-depth profiles of Boulton and Hindmarsh (1987) from Breiđamerkurjökull.

\section{ACKNOWLEDGEMENTS}

I thank C.R. Bentley, D.D. Blankenship, T.J. Hughes, and S.T. Rooney for helpful comments on the manuscript, and I am indebted to J.S. Walder for numerous suggestions and criticisms, not all of which are answered satisfactorily here. I thank A.N. Mares for manuscript preparation, and C.R. Alley for computerized figure drafting. This work was supported by the U.S. National Science Foundation under grant DPP87-16016. This is contribution number 498 of the Geophysical and Polar Research Center, University of Wisconsin-Madison.

\section{REFERENCES}

Alley, R.B. 1989. Water-pressure coupling of sliding and bed deformation: I. Water system. J. Glaciol., 35(119), $108-118$

Alley, R.B., D.D. Blankenship, C.R. Bentley, and S.T. Rooney. 1986. Deformation of till beneath Ice Stream B, West Antarctica. Nature, 322(6074), 57-59.

Alley, R.B., D.D. Blankenship, C.R. Bentley, and S.T. Rooney. 1987a. Till beneath Ice Stream B. 3. Till deformation: evidence and implications. J. Geophys. Res., 92(B9), 8921-8929.

Alley, R.B., D.D. Blankenship, S.T. Rooney, and C.R. Bentley. 1987b. Till beneath Ice Stream B. 4. A coupled ice-till flow model. J. Geophys. Res., 92(B9), 8931-8940.

Alley, R.B., D.D. Blankenship, S.T. Rooney, and C.R. Bentley. 1989. Water-pressure coupling of sliding and bed deformation: III. Application to Ice Stream B, Antarctica. J. Glaciol., 35(119), 130-139.

Blankenship, D.D., C.R. Bentley, S.T. Rooney, and R.B. Alley. 1987. Till beneath Ice Stream B. 1. Properties derived from seismic travel times. J. Geophys. Res., 92(B9), 8903-8912.

Boulton, G.S. 1979. Processes of glacier erosion on different substrata. J. Glaciol., 23(89), 15-38.

Boulton, G.S. and D.L. Dent. 1974. The nature and rates of post-depositional changes in recently deposited till from south-east Iceland. Geogr. Ann., 56A(3-4), 121-134.

Boulton, G.S. and R.C.A. Hindmarsh. 1987. Sediment deformation beneath glaciers: rheology and gelogical consequences. J. Geophys. Res., 92(B9), 9059-9082.

Boulton, G.S., D.L. Dent, and E.M. Morris. 1974. Subglacial shearing and crushing, and the role of water pressures in tills from south-east Iceland. Geogr. Ann., 56A(3-4), 135-145

Brown, N.E., B. Hallet, and D.B. Booth. 1987. Rapid soft bed sliding of the Puget glacial lobe. J. Geophys. Res., 92(B9), 8985-8997.

Clarke, G.K.C. 1987. Subglacial till: a physical framework for its properties and processes. J. Geophys. Res., 92(B9), 9023-9036.

Engelhardt, H.F., W.D. Harrison, and B. Kamb. 1978. Basal sliding and conditions at the glacier bed as revealed by bore-hole photography. J. Glaciol., 20(84), 469-508.

Fahnestock, M. and N. Humphrey. 1988. Borehole water level measurements, Columbia Glacier, AK. [Abstract.] Ice, 86, 25-26.

Fowler, A.C. 1987. A theory of glacier surges. J. Geophys. Res., 92(B9), 9111-9120.

Hampton, M.A. 1979. Buoyancy in debris flows. $J$ Sediment. Petrol., 49(3), 753-758.

Kamb, B. 1970. Sliding motion of glaciers: theory and observation, Rev, Geophys. Space Phys., 8(4), 673-728.

Lliboutry, L. 1987a. Realistic, yet simple bottom boundary conditions for glaciers and ice sheets. J. Geophys. Res., 92(B9), 9101-9109.

Lliboutry, L. 1987b. Sliding of cold ice sheets. International Association of Hydrological Sciences Publication 170 (Symposium at Vancouver 1987 - The Physical Basis of Ice Sheet Modelling), 131-143.

MacClintock, P. and A. Dreimanis. 1964. Reorientation of till fabric by overriding glacier in the St. Lawrence Valley. Am. J. Sci., 262(1), 133-142.

Meier, M.F. 1989. Relationship between water input, basal water pressure, and sliding of Columbia Glacier, Alaska, U.S.A. (Abstract.) Ann. Glaciol., 12, 214-215.

Mellors, R. Unpublished. The deformation of sub-glacial till: a numerical model. (B.Sc. thesis, Ohio State University, 1986.)

Mellors, R. and I.M. Whillans. 1986. Flow of subglacial 
drift. [Abstract.] AGU Chapman Conference on Fast Glacier Flow, Whistler Village, British Columbia, Canada.

Nye, J.F. 1952. Extrusion flow. Reply to Mr. Joel E. Fisher's comments. J. Glaciol., 2(11), 52-53.

Nye, J.F. 1967. Plasticity solution for a glacier snout. $J$. Glaciol., 6(47), 695-715.

Nye, J.F, 1969. A calculation on the sliding of ice over a wavy surface using a Newtonian viscous approximation. Proc. R. Soc. London, Ser. A, 311, 445-467.

Rodine, J.D. and A.M. Johnson. 1976. The ability of debris, heavily freighted with coarse clastic materials, to flow on gentle slopes. Sedimentology, 23, 213-234.

Sugden, D.E. and B.S. John. 1976. Glaciers and landscape; a geomorphological approach. London, Edward Arnold.

Underwood, E.E. 1970. Quantitative stereology. Reading, MA, Addison-Wesley Publishing Company.

Weertman, J. 1964. The theory of glacier sliding. $J$ Glaciol., 5(39), 287-303.

Weertman, J. 1969. Water lubrication mechanism of glacier surges. Can. J. Earth Sci., 6(4, Pt. 2), 929-939.

Weertman, J. 1972. General theory of water flow at the base of a glacier or ice sheet. Rev. Geophys. Space Phys., 10(1), 287-333.

Weertman, J. and G.E. Birchfield. 1982. Subglacial water flow under ice streams and West Antarctic ice-sheet stability. Ann. Glaciol., 3, 316-320.

MS. received I August 1988 and in revised form 15 October 1988 